\title{
IN VITRO ASSESSMENT OF WATER SORPTION, SOLUBILITY AND SURFACE ROUGHNESS OF COMPOMER AND GIOMER MATERIALS AFTER IMMERSION IN DIFFERENT BEVERAGES
}

\author{
Dalia A. Saba*, Fatma K.I. Abdel Gawad** and Mostafa A. Abd Ellatif ${ }^{* * *}$
}

\begin{abstract}
Objective: The purpose of the present study is to assess the water sorption, solubility and surface roughness of compomer and giomer restorative materials after storage in different immersion media.
\end{abstract}

Materials and Methods: Two resin-based restorative materials were selected for this study: Compomer (Twinky Star) and Giomer (Beautifil II). For water sorption and solubility, 6 disc-shaped specimens of each material were prepared according to manufacturers' instruction. Measurements were done by weighing the samples before and after immersion in distilled water for 28 days and after desiccation. Values were statistically analyzed using student-t test (P-Value $<0.05$ ). For surface roughness, 18 disc-shaped specimens of each material were divided into three subgroups according to the immersion media; Mirinda orange, milk and distilled water as the control. Specimens were kept immersed for 28 days. Average baseline and after immersion surface roughness measurements were recorded using a $3 \mathrm{D}$ digital image processing technique. Values were statistically analyzed using One-way ANOVA (P-Value <0.05)

Results: Twinky Star represented significant lower water sorption and solubility values $(0.181$ $\mathrm{mg} / \mathrm{mm}^{3}$ and $\left.0.179 \mathrm{mg} / \mathrm{mm}^{3}\right)$ when compared to Beautifil II $\left(0.208 \mathrm{mg} / \mathrm{mm}^{3}\right.$ and $\left.0.207 \mathrm{mg} / \mathrm{mm}^{3}\right)$, respectively. No significant difference in the surface roughness values between both materials after the immersion in either distilled water, Mirinda orange or milk. Conclusions: The higher sorption and solubility of Beautifil II compared to Twinky Star might compromise its performance and longevity. Immersion of compomer and giomer in water and sugar-sweetened beverages may seriously reduce the durability of both materials . Mirinda orange could potentially erode both materials.

KEY WORDS: Compomer, giomer, water sorption, solubility, surface roughness, storage media

* Lecturer of Dental Materials Science, Biomaterials Department, Faculty of Oral and Dental Medicine, Cairo University, Cairo, Egypt.

** Lecturer of Pediatric dentistry and Dental Public Health, Faculty of Oral and Dental Medicine, Cairo University, Cairo, Egypt.

*** Lecturer of Dental Materials Science, Biomaterials Department, Faculty of Oral and Dental Medicine, Future University in Egypt (FUE), Cairo, Egypt. 


\section{INTRODUCTION}

Innovations in field of direct restorative materials' manufacturing are continuous nonstopping processes. These advancements aim at combining the merits of good esthetics and mechanical properties of resin composite and the fluoride-releasing capability of conventional glassionomer restorative materials. This ongoing effort has led to the emerging of various restorative materials, namely; resin-modified glass ionomer, polyacid-modified resin composites; compomers and giomers ${ }^{(1-5)}$.

Polyacid-modified resin composites, commonly known as compomers were developed in the early 1990s. The name was derived from its two parents; COMP denoting composite resin and OMERS denoting glass-ionomer. It is composed of inorganic glass particles of glass-ionomer in dehydrated (water-free) polyacid-modified bulky macro-monomers with an appropriate initiator. Setting occurs through the photopolymerization of the acidic monomer; however, compomers absorb water intraorally to begin the acid-base reaction of the glass-ionomer component ${ }^{(1,6-10)}$.

Another group of glass-ionomer-composite hybrid restorative material known as "Giomer" has been developed. Giomer is an anhydrous resinous restorative material which is known as "Pre-reacted glass-ionomer (PRG) composites". Giomer differs from compomer as it contains pre-reacted glassionomer fillers (Flouro-alumino-silicate glass particles) incorporated into silica filled urethane resin matrix. The PRG fillers are fabricated by acid-base reactions between fluoride containing glass and polyacrylic acid in the presence of water. Yet, giomers still have the need to absorb water to maintain fluoride release and recharge properties of glass-ionomer cements ${ }^{(1,6,10-13)}$.

Water sorption, solubility and surface roughness are important tests to characterize resin-based materials. Sorption and solubility affect the materials' biocompatibility, structural integrity, mechanical properties, dimensional and color stability. These properties depend on the composition of resin matrix, degree of conversion, filler type and its volume fraction. Water sorption is a function of the resin matrix and it occurs through diffusioncontrolled process. Sorption results in volume increase and swelling, hydrolytic degradation and decrease in materials mechanical properties.

Solubility is defined as weight loss per unit volume because of immersion for a period of time in saliva or oral fluids. It occurs through leachingout of some material's components due to its dissolution or disintegration. Leaching-out process is affected by the amount of unreacted monomer, leachable material's chemical composition and solvent's chemistry. Therefore, water sorption and solubility can seriously reduce durability and clinical performance of resin-based restorative materials ${ }^{(3-5,12,14-19)}$.

Fluoride release from compomer and giomer encourages their use for restorations in children and adolescents who are among the major consumers of acidic sugary-sweetened beverages. These materials are subjected intermittently or continuously to aggressive media and would suffer from degradation which can be detected by variations in surface roughness. Therefore, investigating surface roughness is important to predict the longevity of the restoration. Higher surface roughness represents a risk factor for accumulation of plaque and stains on dental restoration which in turn may affect friction, wear and optical properties of the restoration ${ }^{(4,10,11,20-25)}$.

Therefore, this study was conducted to assess water sorption, solubility and surface roughness of two resin-based restorative materials; compomer and giomer. The null hypothesis is there will be no difference between both restorative materials regarding the three parameters, even after storage in different immersion media. 


\section{MATERIALS AND METHODS}

This study was conducted using two commercially-available resin-based restorative materials; giomer (Beautifil II, Shofu, Kyoto, Japan), and compomer (Twinky Star, Voco, Germany). Details of the materials used in the study are given in Table 1.

\section{Specimens' preparation}

For measurement of water sorption, solubility and surface roughness, a total of 48 disc-shaped specimens $(1.5 \mathrm{~mm}$ thick $\times 8.5 \mathrm{~mm}$ diameter $)$ were prepared using a split Teflon mold. The uncured materials were carefully injected from one side into the mold to minimize the entrapment of air bubbles. To minimize oxygen inhibition layer, both materials were cured against celluloid matrix strip, which was also used to form the smoothest possible surface for restorations.

Materials in the mold were pressed between two glass slides under hand pressure to extrude any excess material and to produce a smooth flat surface. Before light-curing, the glass slides were removed and specimens were polymerized for 20 seconds from each side using light-emitting diode (LED) light-curing unit (DB-685 Super dual, Coxo, Foshan Coxo Medical Instrument Co, Ltd, Guangdong, China) with an intensity of $>1200 \mathrm{~mW} / \mathrm{cm}^{2}$ for both materials. The light tip was kept in direct contact with the matrix strip. After specimens were removed from the mold, any excess material was removed by a sharp scalpel blade (\# 15) to avoid loose particles attached to the specimens during weighing or immersion ${ }^{(4,12,15,16,26)}$.

\section{Water Sorption and Solubility tests}

For water sorption and solubility tests, a total of 12 disc-shaped specimens were prepared ( $n=6 / g p)$. After specimens' preparation, they were placed into a glass desiccator containing dehydrated silica-gel maintained at $37 \pm 1^{\circ} \mathrm{C}$ and stored for 24 hours. Specimens were then weighed using an electronic balance with an accuracy of \pm 0.0001 g (0.1mg) (Scaltec Instruments. GmbH RudolfHeiligenstadt, Germany). This cycle was repeated until constant weight was achieved, i.e. until the

TABLE (1) The materials, composition, manufacturer and batch number of the materials used in this study

\begin{tabular}{|c|c|c|c|}
\hline Materials & Composition & Manufacturer & Batch number \\
\hline $\begin{array}{l}\text { Twinky Star } \\
\text { (Compomer) }\end{array}$ & $\begin{array}{l}\text { Organic matrix: BisGMA, UDMA, TEGDMA, carboxylic } \\
\text { acid modified methacrylate, camphorquinone, BHT } \\
\text { Filler : Barium aluminium fluorosilicate glass, strontium } \\
\text { fluorosilicate glass, silicon dioxide } \\
\text { Filler loading } 77.8 \% \mathrm{w} / \mathrm{w} \\
\text { Particle size range } 0.4-3.0 \mu \mathrm{m}\end{array}$ & Voco, Germany & 1537598 \\
\hline $\begin{array}{l}\text { Beautifil II } \\
\text { (Giomer) }\end{array}$ & $\begin{array}{l}\text { Organic matrix: Bis-GMA }(7.5 \mathrm{wt} \%) \text { /TEGDMA } \\
(5 \mathrm{wt} \%) \text { resin, Camphorquinone } \\
\text { Filler: Multifunctional glass filler and S-PRG(Surface Pre- } \\
\text { Reacted Glass-ionomer) fillerbased on fluroboroaluminosilicate } \\
\text { glass. } \\
\text { Filler loading: } 83.3 \mathrm{wt} \% \\
\text { Particle size range: } 0.01-4.0 \mu \mathrm{m} \\
\text { Mean }(0.8 \mu \mathrm{m})\end{array}$ & Shofu, Kyoto, Japan. & 071450 \\
\hline
\end{tabular}


mass loss of each specimen was not more than 0.1 $\mathrm{mg}$ within a period of 24 hours to ensure complete dehydration of the specimens. Measurements were repeated three times for each specimen and an average weight was recorded as the dry weight $\left(\boldsymbol{m}_{\mathbf{l}}\right)$. Diameter and thickness of each specimen were measured at 3 and 4 points respectively using a digital electronic caliper. Measurements were taken in order to calculate volume of each specimen (V) in $\mathrm{mm}^{3}$ by the following equation:

\section{$\mathrm{V}=\pi \mathbf{r}^{2} \mathbf{h}$}

where $r$ is the mean specimen radius, $h$ is the mean specimen thickness.

Afterwards, specimens of each material were immersed in $10 \mathrm{ml}$ distilled water in individual glass-vials for total immersion time of 28 days. After 28 days, specimens were removed from water, gently dried on filter paper until become free from visible moisture, waved in air for 15 seconds. Final weight was taken 1 min from time of removal from water. Each specimen was weighed 3 successive times and an average weight was taken. Recorded mass was denoted as $\boldsymbol{m}_{\mathbf{2}}$. After a total immersion time of 28 days, specimens were then reconditioned in desiccators for 28 days using the cycle described above until dried constant mass was obtained again $\left(\boldsymbol{m}_{3}\right)$. Values for water sorption and solubility, in milligram per cubic millimeter $\left(\mathrm{mg} / \mathrm{mm}^{3}\right)$, were calculated using the following equations:

\section{Solubility $=\left(m_{1}-m_{3} / V\right)$ \\ Water sorption $=\left(m_{2}-m_{3} / V\right)$.}

Where $\boldsymbol{m}_{\boldsymbol{1}}$ is the conditioned-initial-dry mass prior to immersion in distilled water;

$\boldsymbol{m}_{2}(\mathrm{t})$ is the saturated mass of specimen after immersion at a specific time $(\mathrm{t})$;

$\boldsymbol{m}_{\mathbf{3}}(\mathrm{t})$ is the reconditioned-final-dry mass;

$\boldsymbol{V}$ is the volume of the specimen ${ }^{(3,4,15-18,27-29)}$.

\section{Surface roughness measurement}

For surface roughness measurement, a total of 36 disc-shaped specimens were prepared as described above. Specimens were divided into two groups ( $n=18 /$ group) according to the type of the material. The groups were further subdivided into six subgroups according to the immersion media ( $n=6 /$ subgroup); Mirinda Orange (Pepsi cola, Cairo, Egypt), milk (Almarai, Egypt) and distilled water as the control. Before immersion, baseline surface roughness (Ra) value was recorded for each specimen. Afterwards, each specimen was immersed separately in a closed individual glassvial containing $10-\mathrm{ml}$ of test immersion medium. Specimens were immersed in the different media for 28 days in an incubator at $37^{\circ} \mathrm{C}$. All immersion media were changed every 48 hours. Immersion media used were from newly opened container on each time interval. By the end of the 28 immersion days, specimens were taken out of solutions, and rinsed with distilled water. After immersion, the same surface of each specimen that was previously measured for surface roughness was reevaluated in a similar manner to that for the baseline condition. Difference in surface roughness of each specimen before and after immersion was calculated and the total mean surface roughness $(\mathrm{Ra})$ for each group was recorded ${ }^{(4,30)}$.

For surface roughness measurements, measuring technique based on digital image processing technology proposed by Zhongxiang et al. 2009 and Abouelatta 2010 was used. The system consists of two major parts; hardware and software. The hardware consists of: stereomicroscope (Zeiss stereomicroscope, Technival 2), digital camera (Canon, USA), halogen lamp, X, Y bidirectional laboratory bench and a computer. The software transfers the 2D images into numerical values representing the surface roughness values ${ }^{(31,32)}$. 


\section{Statistical analyses}

Statistical analysis was performed using Statistical Package for Social Sciences, Version 20 (SPSS Inc., an IBM company, USA) for Windows. Differences between the two materials, regarding data of water sorption and solubility were analyzed using Student-t test. For surface roughness, values were analyzed using one-way analysis of variance ANOVA. P-values less than 0.05 were considered statistically significant. Differences in surface roughness between different media for the same material were analyzed using Bonferroni t-test

\section{RESULTS}

\section{Water sorption}

Statistical analysis for mean and standard deviation values of water sorption of the two groups is shown in Table 2. Twinky Star represented significant lower (87\%) water sorption values when compared to Beautifil II.

TABLE (2) Means and standard deviation (SD) values (in $\mathrm{mg} / \mathrm{mm}^{3}$ ) for the water sorption

\begin{tabular}{|c|c|c|}
\hline Material & Mean & SD \\
\hline Twinky Star & $\mathbf{0 . 1 8 1}$ & 0.007 \\
\hline Beautifil II & $\mathbf{0 . 2 0 8}$ & 0.01 \\
\hline P-value & $\leq 0.001 *$ & \\
\hline
\end{tabular}

*: Significant difference at $P<0.05$

\section{Solubility}

Statistical analysis for the mean and standard deviation values of solubility of the two groups is shown in Table 3. Twinky Star represented significant lower $(86.5 \%)$ solubility values when compared to Beautifil II.

TABLE (3) Means and standard deviation (SD) values (in $\mathrm{mg} / \mathrm{mm}^{3}$ ) for the solubility

\begin{tabular}{|c|c|c|}
\hline Material & Mean & SD \\
\hline Twinky Star & $\mathbf{0 . 1 7 9}$ & 0.007 \\
\hline Beautifil II & $\mathbf{0 . 2 0 7}$ & 0.01 \\
\hline P-value & \multicolumn{2}{|c|}{$\leq 0.001^{*}$} \\
\hline
\end{tabular}

*: Significant difference at $P<0.05$

\section{Surface roughness:}

Statistical analysis for mean and standard deviation values of surface roughness for the two groups, after the immersion for 28 days in the three immersion media, is shown in Table 4. No significant difference in the surface roughness between both materials after immersion in either distilled water, Mirinda orange or milk. Within Beautifil II groups, no significant difference in surface roughness values after immersion in the three immersion media. However, within Twinky Star groups, immersion in Mirinda orange showed significant higher surface roughness than after immersion in distilled water.

TABLE (4) Means and standard deviation (SD) values (in $\mu \mathrm{m}$ ) for the surface roughness after immersion in the three immersion media

\begin{tabular}{|c|c|c|c|c|c|c|c|}
\hline Media & \multicolumn{2}{|c|}{ Distilled water } & \multicolumn{2}{|c|}{ Mirinda Orange } & \multicolumn{2}{|c|}{ Milk } & \multirow{2}{*}{ P-value } \\
\hline Material & Mean & SD & Mean & SD & Mean & SD & \\
\hline Twinky Star & $0.66^{\mathrm{a}}$ & 0.36 & $2.72^{b}$ & 0.86 & $1.68^{\mathrm{ab}}$ & 0.90 & $0.016^{*}$ \\
\hline Beautifil II & 2.03 & 1.04 & 4.77 & 1.69 & 2.64 & 1.45 & 0.283 \\
\hline P-value & \multicolumn{2}{|c|}{0.086} & \multicolumn{2}{|c|}{0.258} & \multicolumn{2}{|c|}{0.257} & \\
\hline
\end{tabular}

*: Significant difference at $P<0.05$, Different letters are significantly different 


\section{DISCUSSION}

From the results of this study, it was found that water sorption and solubility values of giomer (Beautifil II) were higher than those of compomer (Twinky Star). However, the surface roughness values after immersion in the three immersion media for 28 days were similar for both materials investigated; therefore, the null hypothesis was partly rejected.

Release of fluoride from any restorative material is mediated by its capability for water diffusion. However, excessive absorption of large amounts of water may cause chemical degradation of the material, debonding of the matrix and release of residual monomers ${ }^{(12,33)}$.

Two methods for calculating water sorption were identified in previous studies. Some studies calculate water sorption by subtracting the conditioned-initialdry mass prior to immersion from the saturated mass of specimen after immersion. However, this method does not take into consideration the amount amount of leached out materials ${ }^{(9-12)}$. Therefore, to be more precise, in this study, the water sorption was calculated by subtracting the reconditioned-finaldry mass from the saturated mass of specimen after immersion ${ }^{(3,4,15-18,27-29)}$.

McCabe and Rusby 2004 reported that the nature and hydrophilicity of the resin matrix is a major parameter which may regulate rate and extent of water diffusion ${ }^{(34)}$.

Both investigated materials contain bisphenolA-glycol dimethacrylate (Bis-GMA) and triethylene glycol dimethacrylate (TEGDMA) oligomers in their matrices. These types of polymers are known of their high hydrophilic nature that might be attributed to strong hydrogen bonds formed between their hydroxyl groups and water molecules. This explains their increasing tendency for water sorption. Compared to other oligomers, TEGDMA is more heterogeneous in composition and has higher flexibility. The more the heterogeneous network, the larger are the micropores created between polymer clusters and the larger is the quantity of absorbed water. Being flexible, TEGDMA chains become more liable to swell and accommodate higher amounts of water. This explains the ability of both materials to absorb water; however, Twinky Star showed significantly lower water sorption than Beautifil II. This might be due to the presence of urethane dimethacrylate (UDMA) oligomer in the composition of the former material which is more hydrophobic than other mentioned oligomers ${ }^{(26)}$.

Nevertheless, resin matrix composition may not be the only factor that affects the amount of absorbed water. Giomers differ from compomers in presence of surface pre-reacted glass polyacid zones that become a component of the giomer filler structure. These zones have the capability to generate an osmotic pressure that potentially increases water sorption. Formation of these zones in compomer is very limited and delayed to occur compared to those in giomers. This is because in compomers these zones are formed as a result of the acid-base reaction that follows water absorption. This might explain why Beautifil II showed greater water sorption than Twinky Star (12,33-35).

The results of the current study was in agreement with the study of McCabe \& Rusby 2004, which investigated water sorption capacity of different compomer, giomer and fluoride-containing composite materials and reported that giomer exhibited higher water sorption when compared with other tested materials ${ }^{(34)}$.

Similarly, Gonulol et al. 2015 found that Beautifil II had significantly greater water sorption than two nanohybrid composite resins ${ }^{(12)}$.

Contrary, solubility of resin matrix goes together with its ability for water sorption. This is because unreacted components can only be leached-out when water penetrates the material ${ }^{(36)}$.

Moreover, the higher solubility of Beautifil II could be clarified by the glass fluoridation method that markedly differs than that in compomer. 
The pre-reacted glass-ionomer technology applied in giomer manufacturing is responsible for formation of a stable phase of GIC in the material's matrix. The more extensive acid-base reaction and hydrogel layer of glass fillers are responsible for the higher amount of fluoride release in giomers when compared to compomers. This in turn increases the amount of solubility ${ }^{(37,38)}$.

This is in consistency with Gonulol et al. 2015 which stated that Beautifil II, showed the highest fluoride-release and the highest solubility among other tested composites ${ }^{(12)}$.

Moreover, the difference in solubility between both resin-based materials might be attributed to the density of cross-links and degree of conversion within each material. Floyd \& Dickens 2006 stated that UDMA-based polymers had more crosslinks than Bis-GMA-based polymers. The study also stated that UDMA-containing polymers had significantly higher conversion (76\% to $87 \%$ ) degrees than Bis-GMA containing ones (54\% to $85 \%)^{(39)}$. Therefore, Bis-GMA polymers have higher amounts of leachable monomer than UDMA polymers. Consequently, the more cross-linked the polymer network and the higher the conversion degree, the less the water sorption and solubility of the resin-based material ${ }^{(17)}$.

In the current study, surface roughness assessment was chosen as it is well-known that worn or roughened surfaces encourage bacterial colonization and plaque accumulation. This, in turn, increases risks for caries and periodontal inflammation ${ }^{(11,24,25)}$.

Surface roughening may be a result of erosion, which is derived from the Latin verb 'Erodere erosi, Erosum' (to corrode). It describes the process of gradual destruction of the surface of something, usually by electrolytic or chemical process. Inside oral cavity, erosion of restorative material could take place from exposure to acidic food or drinks ${ }^{(22,25)}$.
Mirinda orange was selected in this study, as it is highly acidic with a low $\mathrm{pH}$ around 2.85 , as reported by Hamouda 2011. Moreover, Mirinda contains citric acid. It has been stated that citric acid is the most aggressive storage medium for glass-ionomer cements, and likewise for compomers ${ }^{(4)}$.

In addition, milk was selected because it is almost neutral with $\mathrm{pH}$ around 6.34 and because it is widely consumed by children. Distilled water represented the control medium throughout this study ${ }^{(4)}$.

The acidic attack presented by the low $\mathrm{pH}$ of the Mirinda orange might have resulted in the loss of structural ions from the glassy phase of both the compomer and giomer. This result is in consistency with the study conducted by Abu-Bakr et al. 2001 that reported that low $\mathrm{pH}$ produced chemical erosion of hybrid restorative materials by acid etching the surface and leaching the principal matrix forming cations $(\mathrm{Na}, \mathrm{Ca}, \mathrm{Al}, \mathrm{Sr})^{(2,4,10)}$.

However, many studies have reported that the erosive potential of an acidic solution is not only related to its $\mathrm{pH}$, but also to the titratable acidity and buffer capacity. Titratable acidity is the amount of alkali needed to be added to an acid to bring it up to a neutral $\mathrm{pH}$. While buffering capacity is the change of the $\mathrm{pH}$ of the immersion solutions towards neutrality. Therefore, low $\mathrm{pH}$ and high titratable acidity of Mirinda orange might indicate its erosive potential $^{(10,25)}$.

Compomers and giomers have been found to have buffering capacity. Buffering capacity has been observed for glass-ionomer cements, and glass ionomer containing restorative materials, but not for conventional composites. It is a property conferred by the acid-base components and might be attributed to ions release ${ }^{(40)}$.

Fujimoto et al. 2010 found that SPRG fillers contained in giomer altered the $\mathrm{pH}$ values of both distilled water and lactic acid closer to neutrality and SPRG filler, like conventional glass-ionomer cements, had a modulating effect on acidic solutions ${ }^{(41)}$. 
Conversely, distilled water was found to affect the surface roughness, which might be attributed again to water sorption and dissolution of resin matrix ${ }^{(11)}$.

Surface roughness of the tested materials immersed in water was less than that in milk; this may be attributed to the higher $\mathrm{pH}$ of water than that of milk ${ }^{(4)}$.

Finally, it has to be stated that from the high results of water sorption and solubility of Beautifil II, high surface roughness values were expected. Increasing sorption results in resin matrix swelling and eventually filler debonding. Consequently, surface roughness was increased. However, surface roughness values of Beautifil II didn't significantly differ from that of Twinky Star as was anticipated. This might be attributed to the higher filler volume of Beautifil II (83.3 wt \%) when compared to that of Twinky Star (77.8 wt \%). Higher filler volume might have played a pivotal role in improving surface quality of Beautifil II ${ }^{(10)}$.

\section{CONCLUSIONS}

1. Higher sorption and solubility of Beautifil II compared to Twinky Star might compromise its performance and longevity.

2. Immersion of compomer and giomer in water and sugar-sweetened beverages may seriously reduce the durability of both materials.

3. Mirinda orange could potentially erode both materials.

\section{ACKNOWLEDGMENTS}

The authors dedicate this work to the soul of Professor Mervat A. Rashed, Professor of Pediatric dentistry, Faculty of Oral and Dental Medicine, Cairo University. Professor Mervat contributed to the conception and design of this study but she passed away before the completion of the work.

\section{REFERENCES}

1. Tay, F., Pashley, E., Huang, C., Hashimoto, M., Sano, H., Smales, R. and Pashley, D. (2001). The Glass-ionomer Phase in Resin-based Restorative Materials. Journal of Dental Research, 80(9), pp.1808-1812.

2. ABU-BAKR, N., HAN, L., OKAMOTO, A. and IWAKU, M. (2001). Evaluation of the Surface Roughness of Compomer by Laser Scanning Microscopy. Dental Materials Journal, 20(2), pp.172-180.

3. Toledano, M., Osorio, R., Osorio, E., Fuentes, V., Prati, C. and García-Godoy, F. (2003). Sorption and solubility of resin-based restorative dental materials. Journal of Dentistry, 31(1), pp.43-50.

4. HAMOUDA, I. (2011). Effects of Various Beverages on Hardness, Roughness, and Solubility of Esthetic Restorative Materials. Journal of Esthetic and Restorative Dentistry, 23(5), pp.315-322.

5. Mousavinasab, S. and Meyers, I. (2009). Flouride release and uptake by glass ionomer cements, compomers and giomers, Reasearch J. Biol. Sci. 4,pp. 609-16.

6. TIAN, F., YAP, A., WANG, X. and GAO, X. (2012). Effect of staining solutions on color of pre-reacted glass-ionomer containing composites. Dental Materials Journal, 31(3), pp.384-388.

7. Nicholson, J. (2007). Water sorption/desorption in polyacid-modified composite resins for dentistry. Journal of Materials Science: Materials in Medicine, 19(4), pp.17131717. G.

8. Yadav, U. Rehani, V. Rana. (2012). A Comparative Evaluation of Marginal Leakage of Different Restorative Materials in Deciduous Molars: An in vitro Study., Int. J. Clin. Pediatr. Dent. 5, pp. 101-107.

9. Musanje, L., Shu, M. and Darvell, B. (2001). Water sorption and mechanical behaviour of cosmetic direct restorative materials in artificial saliva. Dental Materials, 17(5), pp.394-401.

10. Sankar, A., Kumar, M., Kumar, K., Pranitha, K., Kishore, K. and Rajavardhan, K. (2014). Erosive potential of cola and orange fruit juice on tooth colored restorative materials. Annals of Medical and Health Sciences Research, 4(9), p.208.

11. Kooi, T., Tan, Q., Yap, A., Guo, W., Tay, K. and Soh, M. (2012). Effects of Food-simulating Liquids on Surface Properties of Giomer Restoratives. Operative Dentistry, 37(6), pp.665-671. 
12. Gonulol, N., Ozer, S. and Sen Tunc, E. (2014). Water Sorption, Solubility, and Color Stability of Giomer Restoratives. Journal of Esthetic and Restorative Dentistry, 27(5), pp.300-306.

13. Jyothi, K., Kumar, A., Jayashankara, C., Annapurna, S. and Venugopal, P. (2011). Clinical evaluation of giomer- and resin-modified glass ionomer cement in class $\mathrm{V}$ noncarious cervical lesions: An in vivo study. Journal of Conservative Dentistry, 14(4), p.409.

14. Heshmat, H., Banava, S., Zarandi, P. and Faraji,F. (2013). In-Vitro Evaluation of Water Sorption and Solubility of GCem and FujiCem in Water and Acid, J. Islam. Dent. Assoc. IRAN Fall. 2525, pp.193-198.

15. MESE, A., BURROW, M. and TYAS, M. (2008). Sorption and solubility of luting cements in different solutions. Dental Materials Journal, 27(5), pp.702-709.

16. Marghalani, H. (2012). Sorption and solubility characteristics of self-adhesive resin cements. Dental Materials, 28(10), pp.e187-e198.

17. Zankuli, M., Devlin, H. and Silikas, N. (2014). Water sorption and solubility of core build-up materials. Dental Materials, 30(12), pp.e324-e329.

18. Toledano, M., Osorio, R., Osorio, E., Aguilera, F., Romeo, A., de la Higuera, B. and García-Godoy, F. (2006). Sorption and solubility testing of orthodontic bonding cements in different solutions. Journal of Biomedical Materials Research Part B: Applied Biomaterials, 76B(2), pp.251-256.

19. PEARSON, G. and LONGMAN, C. (1989). Water sorption and solubility of resin-based materials following inadequate polymerization by a visible-light curing system. Journal of Oral Rehabilitation, 16(1), pp.57-61.

20. Pedrini, D., Candido, M. and Rodrigues, A. (2003). Analysis of surface roughness of glass-ionomer cements and compomer. Journal of Oral Rehabilitation, 30(7), pp.714-719.

21. Bagis, B., Tüzüner, T., Turgut, S., Korkmaz, F., Baygın, Ö. and Bağış, Y. (2014). Effects of Protective Resin Coating on the Surface Roughness and Color Stability of ResinBased Restorative Materials. The Scientific World Journal, 2014, pp.1-7.

22. Maganur, P., Satish, V., Prabhakar, A. and Namineni, S. (2015). Effect of Soft Drinks and Fresh Fruit Juice on Surface Roughness of Commonly used Restorative Materials. International Journal of Clinical Pediatric Dentistry, 8, pp.1-5.
23. Owens BM, Mallette JD. (2014). Effects of Carbonated Cola Beverages, Sports and Energy Drinks and Orange Juice on Primary and Permanent Enamel Dissolution, Austin J. Dent. 1,pp.1-7.

24. TURSSI, C., HARA, A., SERRA, M. and RODRIGUES, A. (2002). Effect of storage media upon the surface micromorphology of resin-based restorative materials. Journal of Oral Rehabilitation, 29(9), pp.864-871.

25. Bajwa, N. and Pathak, A. (2014). Change in Surface Roughness of Esthetic Restorative Materials after Exposure to Different Immersion Regimes in a Cola Drink. ISRN Dentistry, 2014, pp.1-6.

26. Abdel Hamid, DM. and Abou Nawareg, MM. (2016) Hydrolytic Degradation of Three Resin Composites Based on Different Monomer Systems, Egypt. Dent. J. 58, 28672879 .

27. Troca, V., Fernandes, K., Terrile, A., Marcucci, M., Andrade, F. and Wang, L. (2011). Effect of green propolis addition to physical mechanical properties of glass ionomer cements. Journal of Applied Oral Science, 19(2), pp.100-105.

28. Soliman, TA., Tubaigy, KM. , Raffat, EM. and Al-Agha, EI. (2015) In Vitro Solubility and Wear Rates of Silorane and Dimethacrylate Resin Based Composite Restorative Materials under Different pH Conditions., J. Int. Oral Heal. JIOH. 7, 9-13.

29. Dinakaran, D. (2014). Sorption and Solubility Characteristics of Compomer, Conventional and Resin Modified Glass-Ionomer Immersed In Various Media. IOSR Journal of Dental and Medical Sciences, 13(3), pp.41-45.

30. Hafez, R., Ahmed, D. , Yousry, M., El-Badrawy, W. and El-Mowafy, O. (2010). Effect of in-office bleaching on color and surface roughness of composite restoratives., Eur. J. Dent. 4 ,118-127.

31. Zhongxiang, H., Lei, Z., Jiaxu, T., Xuehong, M. and Xiaojun, S. (2008). Evaluation of three-dimensional surface roughness parameters based on digital image processing. The International Journal of Advanced Manufacturing Technology, 40(3-4), pp.342-348.

32. Abouelatta, OB. (2010). 3D Surface Roughness Measurement Using a Light Sectioning Vision System, Proc. World Congr. Eng. I.

33. NSW, N. (2016). GIOMER- The Intelligent Particle (New Generation Glass Ionomer Cement). International Journal of Dentistry and Oral Health, 2(4). 
34. McCabe, J. and Rusby, S. (2004). Water absorption, dimensional change and radial pressure in resin matrix dental restorative materials. Biomaterials, 25(18), pp.4001-4007.

35. Sideridou, I. (2003). Study of water sorption, solubility and modulus of elasticity of light-cured dimethacrylatebased dental resins. Biomaterials, 24(4), pp.655-665.

36. Boaro, L., Gonçalves, F., Guimarães, T., Ferracane, J., Pfeifer, C. and Braga, R. (2013). Sorption, solubility, shrinkage and mechanical properties of "low-shrinkage" commercial resin composites. Dental Materials, 29(4), pp.398-404.

37. Itota, T., Carrick, T., Yoshiyama, M. and McCabe, J. (2004). Fluoride release and recharge in giomer, compomer and resin composite. Dental Materials, 20(9), pp.789-795.
38. Bansal, R. (2015). A Comparative Evaluation of the Amount of Fluoride Release and Re-Release after Recharging from Aesthetic Restorative Materials: An in Vitro Study. Journal of Clinical and Diagnostic Research.

39. Floyd, C. and Dickens, S. (2006). Network structure of Bis-GMA- and UDMA-based resin systems. Dental Materials, 22(12), pp.1143-1149.

40. Nicholson, J. (2007). Polyacid-modified composite resins ("compomers") and their use in clinical dentistry. Dental Materials, 23(5), pp.615-622.

41. Fujimoto, Y., Iwasa, M., Murayama, R., Miyazaki, M., Nagafuji, A. and Nakatsuka, T. (2010). Detection of ions released from S-PRG fillers and their modulation effect. Dental Materials Journal, 29(4), pp.392-397. 